\title{
Iron and zinc variation along the grain length of different Thai rice varieties
}

\author{
Suwannee Laenoi ${ }^{\mathrm{a}, *}$, Chanakan Prom-u-thai ${ }^{\mathrm{a}, \mathrm{b}}$, Bernard Dell ${ }^{\mathrm{c}}$, Benjavan Rerkasem ${ }^{\mathrm{d}}$ \\ a Agronomy Division, Department of Plant and Soil Sciences, Faculty of Agriculture, \\ Chiang Mai University, Chiang Mai 50200 Thailand \\ b Lanna Rice Research Centre, Chiang Mai University, Chiang Mai 50200 Thailand \\ c School of Veterinary and Life Sciences, Murdoch University, Perth 6150, Australia \\ d Plant Genetic Resource and Nutrition Laboratory, Chiang Mai University, Chiang Mai 50200 Thailand
}

*Corresponding author, e-mail: suwanneecmu@gmail.com

Received 4 Jun 2014

Accepted 2 Nov 2015

\begin{abstract}
This study examined the distribution of iron ( $\mathrm{Fe}$ ) and zinc ( $\mathrm{Zn}$ ) along the grain length of seven rice varieties. The experiment was conducted in a completely randomized design with two factors (variety and grain fraction) and three independent replications. Samples of brown and white rice of six common Thai rice varieties and a high Fe and $\mathrm{Zn}$ variety, IR68144, were transversely cut into three fractions per grain (basal, middle, and distal) with approximately the same length in each fraction. The concentration of Fe and $\mathrm{Zn}$ was determined by the dry ashing method and quantified using atomic absorption spectrometry. The middle grain fraction of brown rice was found to have the lowest Fe and $\mathrm{Zn}$ with greater concentration of $\mathrm{Fe}$ and $\mathrm{Zn}$ in the basal (embryo end) than the other fractions. The rice varieties differed in the amount of Fe and $\mathrm{Zn}$ allocated to different fractions of the endosperm (white rice). The potential for loss of Fe and $\mathrm{Zn}$ during milling due to their uneven distribution along the grain length will become more significant when higher nutrient concentrations are involved, such as those achieved by biofortification efforts. Micronutrient distribution needs to be taken into consideration to ensure that rice consumers benefit from Fe and Zn biofortification.
\end{abstract}

KEYWORDS: grain fraction, micronutrient distribution

\section{INTRODUCTION}

Human malnutrition from Fe and $\mathrm{Zn}$ are the most prevalent nutritional disorders in developing countries of Asia where the population has limited consumption of foods rich in Fe and Zn such as meat and dairy products, and derive most of their nutritional as well as calorie needs from rice ${ }^{1}$. Previous studies have reported a wide range in Fe and $\mathrm{Zn}$ concentrations in brown rice (caryopsis with intact pericarp and embryo) of different genotypes, e.g., 4-24 mg $\mathrm{Fe} / \mathrm{kg}$ and $14-58 \mathrm{mg} \mathrm{Zn/kg}$ in a germplasm collection at the International Rice Research Institute ${ }^{2}$ and 6-16 $\mathrm{mg} \mathrm{Fe} / \mathrm{kg}$ and $17-59 \mathrm{mg} \mathrm{Zn/kg}$ among Thai rice varieties ${ }^{3}$. Based on such information, breeding, and selection of Fe and $\mathrm{Zn}$ rich rice genotypes has been suggested as a means to increase the intake of these nutrients ${ }^{4,5}$.

Rice grains are harvested as rough rice or paddy (husk enclosed caryopsis). Pre-cooking processing includes removal of the husk that produces brown rice, followed by milling by a polishing action leav- ing just the white endosperm or white rice (dehusked caryopsis without pericarp, the aleurone, some subaleurone cells and embryo), the form most commonly preferred by rice consumers. Iron and $\mathrm{Zn}$ have been shown to have particular localization patterns in different parts of the rice seed, being most concentrated in the aleurone, followed by the embryo and least concentrated in the endosperm ${ }^{3,6}$. Zinc has also been reported to be much more concentrated in the dorsal than the ventral section of rice grain ${ }^{7}$. Due to the removal of the aleurone and embryo, the concentrations of $\mathrm{Fe}$ and $\mathrm{Zn}$ are reduced in white rice, ranging from $2-11 \mathrm{mg} \mathrm{Fe} / \mathrm{kg}$ and 10-40 mg Zn/ $/ \mathrm{kg}^{3,8-10}$. Furthermore, rice varieties can differ significantly in the loss of Fe and $\mathrm{Zn}$ by milling ${ }^{3}$.

During the process of rice milling, some grains are broken; those that remain more than three quarters of the full grain length are known in the rice trade as head rice, those with shorter pieces are graded as substandard, broken rice ${ }^{11}$. The more stringent standard in Thailand requires that head 
rice must be at least four-fifths of the full grain length ${ }^{12}$. The price of milled rice is determined by the percentage of head rice, with $100 \%$ head rice receiving the highest price, and prices decreasing with increasing percentage of broken rice. Our preliminary investigation found higher concentrations of $\mathrm{Fe}$ and $\mathrm{Zn}$ in broken rice than in whole grain ${ }^{13}$. The rice with lower percentage of head rice, e.g., $20-45 \%$ broken, is consumed by people with lower incomes. Thus the intake of Fe and Zn by different groups of rice consumers may depend on the distribution of these nutrients along the grain length and the position of grain breakage. This study therefore evaluates variation in the $\mathrm{Fe}$ and $\mathrm{Zn}$ content of 6 common Thai rice varieties and a high $\mathrm{Fe}$ and $\mathrm{Zn}$ genotype IR68144-2B-2-2-3 in 3 transverse fractions along the grain length. Samples of broken rice from the market were also examined for the proportion of the different grain fractions and $\mathrm{Fe}$ and $\mathrm{Zn}$ concentrations.

\section{MATERIALS AND METHODS}

\section{Rice sample preparation}

Six common paddy Thai rice varieties (KDML105, PTT1, SPR1, PSL1, CNT1, and CNT80) and IR68144 (IR68144-2B-2-2-3) were grown in the field on Sansai series soil under wetland condition at Chiang Mai University $\left(18^{\circ} 47^{\prime} \mathrm{N}, 98^{\circ} 57^{\prime} \mathrm{E}\right)$ during the rainy season, the main rice season in Thailand. Fourweek-old seedlings of each genotype were transplanted into $20 \times 40 \mathrm{~m}$ plots at $0.25 \times 0.25 \mathrm{~m}$ spacing. The field was kept flooded under $0.1-0.2 \mathrm{~m}$ of water until maturity. Four weeks after transplanting $\mathrm{N}(25 \mathrm{~kg} / \mathrm{ha})$ and $\mathrm{P}(14 \mathrm{~kg} / \mathrm{ha})$ were applied, followed by $\mathrm{N} 63 \mathrm{~kg} / \mathrm{ha} 2$ weeks later. Seeds of all varieties were harvested at maturity. The experiment was conducted in completely randomize design with two factors (variety and grain fraction) and three independent replications. One hundred grams of each variety was de-husked with a laboratory husker (model P-1, Ngek Seng Huat) to produce brown rice. All relevant parts of the husker were Teflon-coated to avoid Fe contamination during the husking process ${ }^{8}$. After husking, $30 \mathrm{~g}$ subsamples of the brown rice were milled for $30 \mathrm{~s}$ with laboratory mill (model K-1, Ngek Seng Huat) to produce white rice. Subsamples of brown and unbroken white rice were cut transversely into three fractions of approximately the same length with a Teflon knife (Personna, Verona VA, USA), identified as basal (embryo end), middle, and distal (the opposite end to the embryo) fractions.

\section{Determination of $\mathrm{Fe}$ and $\mathrm{Zn}$}

Distribution of Fe and $\mathrm{Zn}$ along the grain length was evaluated by atomic absorption spectrophotometer (Hitachi Model Z-8230) after dry ashing at $535^{\circ} \mathrm{C}$ for $8 \mathrm{~h}^{14}$. The distribution of $\mathrm{Fe}$ and $\mathrm{Zn}$ along the grain length of white rice was determined from the nutrient content in the different grain fractions. The experiment was conducted in 3 replications with completely randomized design.

\section{Proportion of grain fraction among market broken rice}

Two sets of the bulked broken rice samples were collected from the local retail market in Chiang Mai. The first set of samples consisting of 4 samples of whole grain (100\% head rice) and 4 samples of broken grain of unknown variety from separated bulk samples, were analysed for Fe and Zn, in triplicate. The second set of samples were 16 samples of non-glutinous aromatic Thai Hom Mali (the most common broken rice on sale in the retail market, produced largely from the variety KDML105). Fe and $\mathrm{Zn}$ were determined from the basal, middle and distal grain fractions. For each broken rice sample, the proportion by weight and number of basal (identified by the scar left after removal of the embryo), middle (sharp cross grain break at both ends) and distal (sharp cross grain break at one end and smooth grain tip at the other end) grain fractions were determined from 3 replicates of $10 \mathrm{~g}$ subsamples.

\section{Data analysis}

The $\mathrm{Fe}$ and $\mathrm{Zn}$ concentrations and proportion of broken fractions were subjected to ANOVA. Data on proportion were arcsine transformed before analysis. Significant differences between means were determined by the least significant difference (LSD) at $p<0.05$. Correlation analysis was used to test the significance of each correlation. All statistical analyses were performed using Statistic 8 (analytical software, SXW).

\section{RESULTS}

Based on their brown rice contents, all Thai rice varieties had low Fe $(<13 \mathrm{mg} \mathrm{Fe} / \mathrm{kg})$, and $\mathrm{Zn}(<$ $30 \mathrm{mg} \mathrm{Zn} / \mathrm{kg}$ ), while IR68144 was high in both Fe (16 mg Fe/kg) and Zn (40 mg Zn/kg). Distribution of both Fe and Zn (Table 1) along the length of brown rice grain varied significantly among the rice varieties, but did not seem to be related to the low or high $\mathrm{Fe} / \mathrm{Zn}$ status of the varieties. In general, the 
Table 1 Iron and zinc concentrations in 3 transverse fractions of brown rice of seven varieties.

\begin{tabular}{|c|c|c|c|c|c|c|c|c|c|c|c|c|}
\hline \multirow{3}{*}{$\begin{array}{l}\text { Variety } \\
\text { KDML105 }\end{array}$} & \multicolumn{6}{|c|}{ Fe concentration $(\mathrm{mg} / \mathrm{kg})^{\dagger}$} & \multicolumn{6}{|c|}{$\mathrm{Zn}$ concentration $(\mathrm{mg} / \mathrm{kg})^{\dagger}$} \\
\hline & \multicolumn{2}{|c|}{ Basal } & \multicolumn{2}{|c|}{ Middle } & \multicolumn{2}{|c|}{ Distal } & \multicolumn{2}{|c|}{ Basal } & \multicolumn{2}{|c|}{ Middle } & \multicolumn{2}{|c|}{ Distal } \\
\hline & 8.9 & $\mathrm{bB}$ & 5.2 & $\mathrm{aAB}$ & 6.3 & $\mathrm{aA}$ & 30.8 & $\mathrm{cC}$ & 20.9 & $\mathrm{aA}$ & 26.2 & bB \\
\hline PTT1 & 9.4 & $\mathrm{cB}$ & 4.8 & $\mathrm{aA}$ & 6.5 & $\mathrm{bA}$ & 29.7 & $\mathrm{cBC}$ & 19.5 & $\mathrm{aA}$ & 27.3 & bB \\
\hline SPR1 & 6.2 & $\mathrm{aA}$ & 6.3 & $\mathrm{aB}$ & 8.2 & bB & 15.5 & $\mathrm{aA}$ & 20.6 & bA & 26.3 & $\mathrm{cB}$ \\
\hline PSL1 & 6.3 & $\mathrm{aA}$ & 5.6 & $\mathrm{aAB}$ & 5.9 & $\mathrm{aA}$ & 17.6 & $\mathrm{aA}$ & 18.6 & $\mathrm{aA}$ & 25.1 & bB \\
\hline CNT1 & 15.4 & $\mathrm{cD}$ & 7.8 & $\mathrm{aC}$ & 9.3 & $\mathrm{bBC}$ & 28.1 & $\mathrm{cB}$ & 19.4 & $\mathrm{aA}$ & 22.5 & bA \\
\hline CNT80 & 11.7 & $\mathrm{cC}$ & 6.3 & $\mathrm{aB}$ & 9.9 & $\mathrm{bC}$ & 28.3 & $\mathrm{bB}$ & 19.6 & $\mathrm{aA}$ & 26.9 & $\mathrm{bB}$ \\
\hline IR68144 & 17.3 & $c E$ & 10.1 & $\mathrm{aD}$ & 13.7 & $\mathrm{bD}$ & 40.9 & $\mathrm{cD}$ & 29.4 & $\mathrm{aB}$ & 38 & $\mathrm{bC}$ \\
\hline Mean & 10.7 & $c$ & 6.5 & $\mathrm{a}$ & 9 & $\mathrm{~b}$ & 27.3 & $\mathrm{~b}$ & 21.1 & $\mathrm{a}$ & 27.5 & $\mathrm{~b}$ \\
\hline
\end{tabular}

${ }^{\dagger}$ Effects by F-test: Variety (V), $p<0.001$; Grain fraction (F), $p<0.001 ; \mathrm{V} \times \mathrm{F}, p<0.001$.

Significant difference (by $\mathrm{LSD}_{0.05}$ ) between grain fractions in each variety indicated by different lowercase letters and between varieties for each grain fraction by different uppercase letters.

Table 2 Iron and zinc concentrations in 3 fractions of white rice of seven varieties.

\begin{tabular}{|c|c|c|c|c|c|c|c|c|c|c|c|c|}
\hline \multirow{3}{*}{$\begin{array}{l}\text { Variety } \\
\text { KDML105 }\end{array}$} & \multicolumn{6}{|c|}{ Fe concentration $(\mathrm{mg} / \mathrm{kg})^{\dagger}$} & \multicolumn{6}{|c|}{ Zn concentration $(\mathrm{mg} / \mathrm{kg})$} \\
\hline & \multicolumn{2}{|c|}{ Basal } & \multicolumn{2}{|c|}{ Middle } & \multicolumn{2}{|c|}{ Distal } & \multicolumn{2}{|c|}{ Basal } & \multicolumn{2}{|c|}{ Middle } & \multicolumn{2}{|c|}{ Distal } \\
\hline & 4.5 & $\mathrm{abB}$ & 3.7 & $\mathrm{aAB}$ & 4.9 & $\mathrm{bC}$ & 18.9 & $\mathrm{aB}$ & 19.6 & $\mathrm{aA}$ & 24.3 & $\mathrm{bB}$ \\
\hline PTT1 & 5.9 & $\mathrm{bC}$ & 4.5 & $\mathrm{aBC}$ & 5.3 & $\mathrm{abC}$ & 22.3 & $\mathrm{aC}$ & 22.6 & $\mathrm{aB}$ & 28.6 & $\mathrm{bC}$ \\
\hline SPR1 & 3.5 & $\mathrm{aA}$ & 3.1 & $\mathrm{aA}$ & 3.9 & $\mathrm{aB}$ & 14.9 & $\mathrm{aA}$ & 19.2 & bA & 24.2 & $\mathrm{cB}$ \\
\hline PSL1 & 4.9 & $\mathrm{bB}$ & 3.0 & $\mathrm{aA}$ & 2.5 & $\mathrm{aA}$ & 19.3 & $\mathrm{aB}$ & 19.3 & $\mathrm{aA}$ & 22.9 & $\mathrm{bAB}$ \\
\hline CNT1 & 4.2 & $\mathrm{aAB}$ & 3.5 & $\mathrm{aA}$ & 3.8 & $\mathrm{aB}$ & 13.6 & $\mathrm{aA}$ & 18.6 & bA & 21.9 & $\mathrm{cA}$ \\
\hline CNT80 & 6.9 & $\mathrm{bD}$ & 4.8 & $\mathrm{aC}$ & 5.5 & $\mathrm{aC}$ & 18.7 & $\mathrm{aB}$ & 19.4 & $\mathrm{aC}$ & 24.5 & $\mathrm{bB}$ \\
\hline IR68144 & 10.1 & $\mathrm{bE}$ & 8 & $\mathrm{aD}$ & 10.8 & $\mathrm{bD}$ & 31.2 & $\mathrm{aD}$ & 30.4 & $\mathrm{aD}$ & 39.3 & bD \\
\hline Mean & 5.7 & $c$ & 4.4 & $\mathrm{a}$ & 5.4 & $\mathrm{~b}$ & 19.8 & $\mathrm{a}$ & 21.3 & $\mathrm{~b}$ & 26.5 & $c$ \\
\hline
\end{tabular}

$\dagger$ Effects by F-test: Variety (V), $p<0.001$; Grain fraction (F), $p<0.001 ; \mathrm{V} \times \mathrm{F}, p<0.01$.

Effects by F-test: Variety (V), $p<0.001$; Grain fraction (F), $p<0.001 ; \mathrm{V} \times \mathrm{F}, p<0.001$.

Significant difference (by $\mathrm{LSD}_{0.05}$ ) between grain fractions in each variety indicated by different lowercase letters designates and between varieties for each grain fraction by different uppercase letters.

middle grain fraction of brown rice was lowest in both Fe and Zn. There were greater concentrations of $\mathrm{Fe}$ and $\mathrm{Zn}$ in the basal (embryo end) than the other fractions of the grain in 5 out of 7 rice varieties. Brown rice of the varieties SPR1 and PSL1 were much more uniform in Fe concentration along the grain length, but their $\mathrm{Zn}$ concentrations were highest in the distal fraction.

The concentrations of $\mathrm{Fe}$ and $\mathrm{Zn}$ in white rice, with the pericarp, the aleurone, some subaleurone cells and embryo removed, were lower than in brown rice in all grain fractions. Milling had different effects on the relative Fe content of the grain fractions (Table 2). The concentration of $\mathrm{Fe}$ in white rice was indistinguishable in the 3 grain fractions of all varieties. SPR1 and CNT1 were about the same in basal and distal fractions while the same fractions from KDML105, PTT1, IR68144 were higher than that from the middle fraction. The basal fraction in PSL1 and CNT80 was higher than both the middle and distal fractions of SPR1 and CNT1 which had similar concentration. The relative $\mathrm{Zn}$ concentrations of the grain fractions were affected by milling differently from those of Fe. White rice $\mathrm{Zn}$ concentration was highest in the distal fraction in all 7 rice varieties, although there were some differences among the varieties in relative $\mathrm{Zn}$ concentration of the 3 grain fractions (Table 2). In SPR1 and CNT1, there was a significant gradient of increasing $\mathrm{Zn}$ in white rice from the basal to distal fraction. In the remaining 5 varieties, the white rice $\mathrm{Zn}$ concentration of the basal and middle fractions was indistinguishable.

The white rice $\mathrm{Fe}$ concentration of the grain fractions was closely correlated with their brown rice Fe $\left(R^{2}=0.51, p<0.001\right)$, and similarly white rice $\mathrm{Zn}$ concentration of the grain fractions was closely correlated with their brown rice $\mathrm{Zn}\left(R^{2}=\right.$ $0.48, p<0.001$ ) (Fig. 1). With white rice Fe content that ranged from $0.06-0.11 \mu \mathrm{g} /$ grain and Zn from 


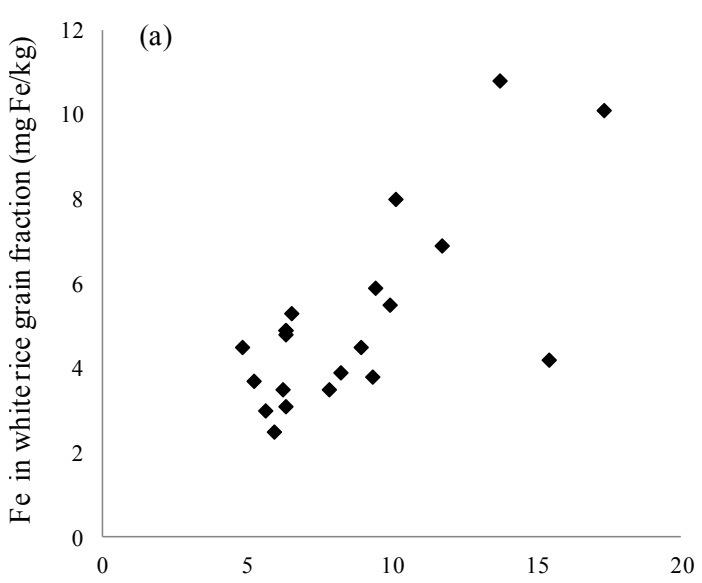

$\mathrm{Fe}$ in brown rice grain fraction $(\mathrm{mg} \mathrm{Fe} / \mathrm{kg})$

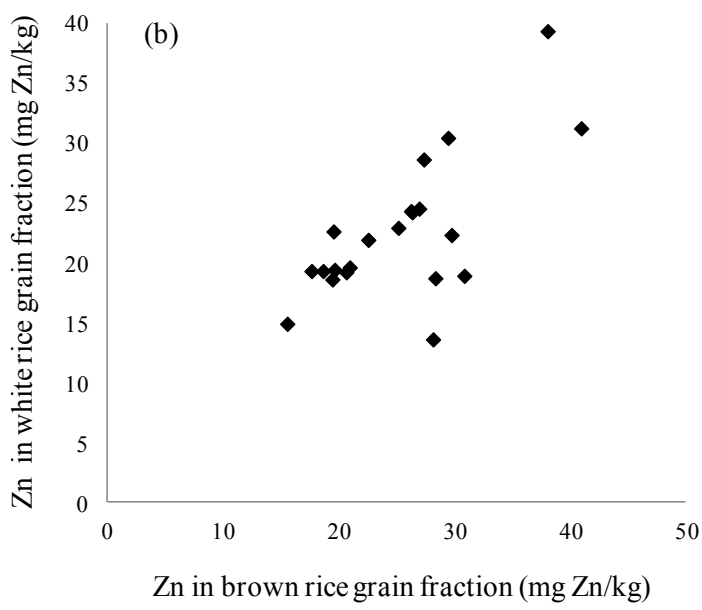

Fig. 1 Relationship between the concentration in brown and white rice grain fractions of (a) Fe, $R^{2}=0.51, p<$ 0.001 and (b) Zn, $R^{2}=0.48, p<0.001$, of 7 rice varieties. (Significance of linear regression by ANOVA).

0.36-0.42 $\mu \mathrm{g} /$ grain, distribution of the nutrients differed significantly among the 3 grain fractions, and differently between Fe and Zn (Fig. 2). About the same amount of Fe was allocated to the 3 grain fractions in 6 of the 7 varieties; the exception was PSL1 which had significantly less Fe in the distal fraction. All 7 rice varieties allocated significantly less Zn to the basal fraction, especially SPR1 and CNT1.

Rice samples from the retail market varied within the same range of $\mathrm{Fe}$ concentration for full grain $(1.3-2.7 \mathrm{mg} / \mathrm{kg}$ ) and broken rice (1.9$2.9 \mathrm{mg} / \mathrm{kg}$ ), and similarly for the range of Zn concentration for full grain $(16.2-21.2 \mathrm{mg} / \mathrm{kg})$ and broken rice (17.8-22.2 mg/kg) (Fig. 3). By weight, broken samples of Thai Hom Mali, a long-grain
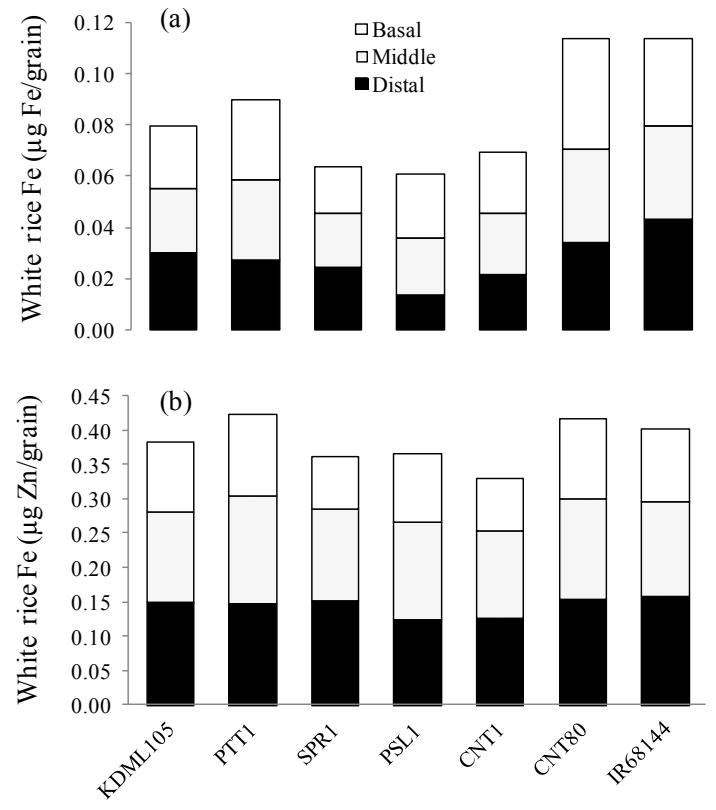

Fig. 2 Distribution of (a) Fe and (b) Zn content along the grain length of white rice of 7 varieties. For Fe, the variety $(\mathrm{V})$, grain fraction $(\mathrm{F})$, and $\mathrm{V} \times \mathrm{F}$ were $p<0.001(0.003)$, not significant $p<0.05$, and $p<0.001(0.005)$, respectively. For $\mathrm{Zn}, \mathrm{V}, \mathrm{G}$, and $\mathrm{V} \times \mathrm{F}$ were $p<0.001(0.008)$, $p<0.001(0.005)$, and $p<0.01(0.014)$, respectively. Numbers in brackets are LSD at $p \leqslant 0.05$.

aromatic rice, in this study were made up mostly of the distal grain fraction, although by their number the middle and distal fractions were dominant in about the same number of samples (Fig. 4).

\section{DISCUSSION}

Significant differences in concentration of the nutrients in white rice grain fractions indicate longitudinal variation in the distribution $\mathrm{Fe}$ and $\mathrm{Zn}$ in the endosperm of rice. The rice varieties also differed in the amount of Fe and $\mathrm{Zn}$ allocated to different fractions of the endosperm. On average, the Fe concentration in the embryo and aleurone is 14 times that in the endosperm; and the embryo $\mathrm{Zn}$ is 9 times while the aleurone $\mathrm{Zn}$ is twice that of the endosperm ${ }^{3}$. In spite of this, there was a close correlation between the Fe concentration of white and brown rice grain fractions, and similarly between the $\mathrm{Zn}$ concentration of white and brown rice grain fractions. The variation in $\mathrm{Fe}$ and $\mathrm{Zn}$ distribution along the endosperm length would have implications for the concentration of these nutrients in milled rice. The loss of grain mass by milling, also called degree of milling, is influenced by mor- 

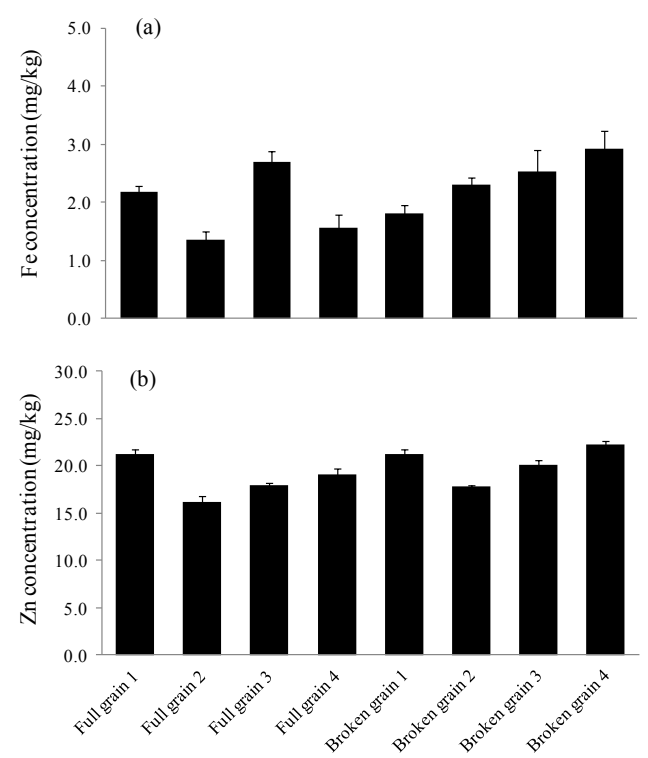

Fig. 3 Concentrations of (a) Fe and (b) $\mathrm{Zn}$ in full and broken grain of the commercial samples from the local market in Chiang Mai, Thailand. Bars represent standard error of means $(n=3)$.

phological characters of the rice grain such as its size and shape, which can differ widely among different rice varieties ${ }^{15-17}$. Loss of Fe during milling in rice varieties grouped by their grain length and shape was closely associated with the degree of milling ${ }^{18}$. Among the long-slender grain Thai rice varieties, however, the loss of $\mathrm{Fe}$ and $\mathrm{Zn}$ during milling is influenced by variation in partitioning of the grain $\mathrm{Fe}$ and $\mathrm{Zn}$ into the aleurone and embryo as well as the degree of milling ${ }^{3}$. The variation in $\mathrm{Fe}$ and $\mathrm{Zn}$ distribution along the length of rice grain found in this study would add another variable to the effect of milling on nutrient concentration of milled rice, with the magnitude and direction of the effect dependent on the grain fraction that is broken off and its nutrient concentration relative to the remainder of the grain. The loss of Fe and Zn during milling in the grain tips would contribute towards loss of the nutrients along with the removal of embryo and aleurone. This, on the other hand, may not be a complete loss, as the cheaper broken rice would become enriched with Fe and Zn.

Grain breakage is a well-known feature of rice milling ${ }^{19,20}$. However, it is as yet unknown which end of the grain is more likely to be broken off, or how this may be influenced by genotype and environment. The observation that the distal grain fraction made up the major proportion by weight of
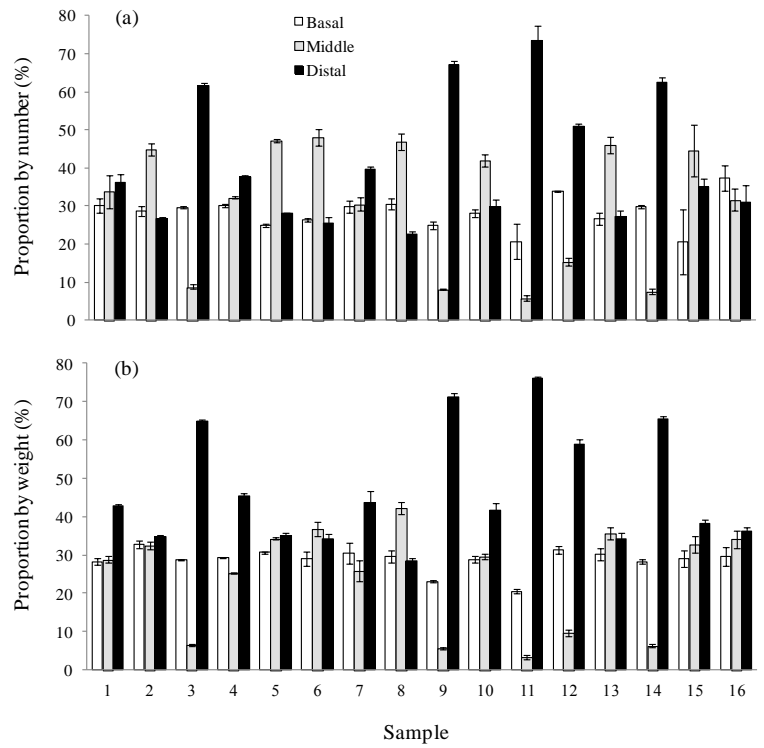

Fig. 4 Proportion of different grain fractions in 16 broken Thai Hom Mali rice samples (a) by number and (b) by weight from the retail market in Chiang Mai, Thailand. Bars represent standard error of means $(n=3)$.

the broken Hom Mali rice samples from the market suggested that this may not happen randomly. As Hom Mali rice is produced largely from the variety KDML105, the loss of distal grain tip with its higher concentrations of $\mathrm{Fe}$ and $\mathrm{Zn}$ during milling would result in significant loss of the nutrients. The limited samples of full grain and broken rice from the market were not distinguishable, neither in their Fe nor their $\mathrm{Zn}$ concentration. With estimated requirement of $8-18 \mathrm{mg} /$ day of Fe $(27 \mathrm{mg}$ Fe for a pregnant woman) and 8-12 mg/day of $\mathrm{Zn}^{21}$ and per capita rice consumption of $0.2-0.3 \mathrm{~kg}^{22,23}$, both full grain and broken rice from the market would have furnished only a small fraction of the nutritional needs of consumers. At the low Fe and $\mathrm{Zn}$ concentration of common rice varieties ${ }^{3,24}$, reflected in the 1$3 \mathrm{mg} / \mathrm{kg} \mathrm{Fe}$ and $16-22 \mathrm{mg} / \mathrm{kg} \mathrm{Zn}$ found in the market rice, and narrow variations in the nutrient concentration along the grain length, loss of Fe and Zn during milling due to grain breakage may be of little consequence. The potential for loss of Fe and Zn during milling due to their uneven distribution along the grain length will, however, become more significant when involving higher concentration of the nutrients, such as achieved by biofortification and/or fortification through parboiling process efforts ${ }^{13}$. For example, milling will affect Fe and $\mathrm{Zn}$ concentration of milled rice more noticeably in high 
$\mathrm{Fe}$ and $\mathrm{Zn}$ varieties like IR68144 than in varieties with lower $\mathrm{Fe}$ and $\mathrm{Zn}$. Loss of grain tips with higher Fe and Zn concentrations during milling will result in lower concentrations of the nutrients in the remaining grain fraction, while the broken rice will become more enriched.

Acknowledgements: The first author is a recipient of a Royal Golden Jubilee PhD scholarship. Financial support for this study from National Research University Programme of Thailand's Commission on Higher Education, Thailand Research Fund (RSA5580056) and Lanna Rice Research Centre, Chiang Mai University, Thailand is gratefully acknowledged.

\section{REFERENCES}

1. Hotz C, Brown KH (2004) Assessment of the risk of zinc deficiency in populations and options for its control. Food Nutr Bull 25, S94-S203.

2. Gregorio GB (2002) Progress in breeding for trace minerals in staple crops. J Nutr 132, 500s-502s.

3. Saenchai C, Prom-u-thai C, Jamjod S, Dell B, Rerkasem B (2012) Genotypic variation in milling depression of iron and zinc concentration in rice grain. Plant Soil 361, 271-8.

4. Welch RM, Graham RD (2004) Breeding for micronutrients in staple food crops from a human nutrition perspective. $J$ Exp Bot 55, 353-64.

5. Bouis HE, Welch RM (2010) Biofortification-a sustainable agricultural strategy for reducing micronutrient malnutrition in the global south. Crop Sci 50, S20-32.

6. Prom-u-thai C, Huang L, Rerkasem B, Thomson G, Kuo J, Saunders M, Dell B (2008) Distribution of protein bodies and phytate-rich inclusions in grain tissues of low and high iron rice genotypes. Cereal Chem 85, 257-65.

7. Jaksomsak P, Sangruan P, Thomson G, Rerkasem B, Dell B, Prom-u-thai C (2014) Uneven distribution of zinc in the dorsal and ventral sections of rice grain. Cereal Chem 91, 124-9.

8. Prom-u-thai C, Fukai S, Godwin DI, Huang L (2007) Genotypic variation of iron partitioning in rice grain. J Sci Food Agr 87, 2049-54.

9. Prom-u-thai C, Rerkasem B, Fukai S, Huang L (2010) Key factors affecting Fe density in Fe-fortifiedparboiled rice: Parboiling conditions, storage duration, external Fe-loading rate and genotypic differences. Food Chem 123, 628-34.

10. Sellappan K, Datta K, Parkhi V, Datt SK (2009) Rice caryopsis structure in relation to distribution of micronutrients (iron, zinc, $\beta$-carotene) of rice cultivars including transgenic indica rice. Plant Sci 177, 557-62.

11. Codex Alimentarius Commission (1995) Codex Stan- dard for Rice, Joint FAO/WHO Food Standard Program, Rome.

12. Ministry of Commerce (1997) Rice Standards B.E. 2540, Ministerial Announcement, Government of Thailand.

13. Prom-u-thai C, Huang L, Rerkasem B (2011) Iron fortification in parboiled rice-a rapid and effective tool for delivering Fe nutrition to rice consumers. Food Nutr Sci 2, 323-8.

14. Allan J (1961) The determination of zinc in agricultural materials by atomic absorption spectrophotometry. Analyst 86, 530-4.

15. Goodman DE, Rao RM (1985) Effect of grain type and milled rice kernel hardness on the head rice yields. J Food Sci 50, 840-2.

16. Jongkaewwattana S, Geng S (2002) Non-uniformity of grain characteristics and milling quality of California rice (Oryza sativa L.) of different maturities. J Agron Crop Sci 188, 161-7.

17. Sison MEGQ, Gregorio GB, Mendioro MS (2006) The effect of different milling times on grain iron content and grain physical parameters associated with milling of eight genotypes of rice (Oryza sativa L.). Philippine J Sci 135, 9-17.

18. Prom-u-thai C, Sanchai C, Rerkasem B, Jamjod S, Fukai S, Godwin ID, Huang L (2007) Effect of grain morphology on degree of milling and iron loss in rice. Cereal Chem 84, 384-8.

19. Bhattacharya KR (1969) Breakage of rice during milling and effect of parboiling. Cereal Chem 46, 478-85.

20. Lyman NB, Jagadish KS, Nalley LL, Dixon BL, Siebenmorgen T (2013) Neglecting rice milling yield and quality underestimates economic losses from hightemperature stress. PLOS ONE 8, e72157.

21. National Academies of Sciences (2004) Dietary Reference Intakes (DRIs): Recommended Intakes for Individuals, Vitamins, Food and Nutrition Board, Institute of Medicine, NAS, Bethesda, MD.

22. Isvilanonda S (2006) Rice consumption in Thailand: the slackening demand. Paper presented at the JSPS Asian Science Seminar on "Development Strategy for Sustainable Food System" during November 26 to December 5, 2006 at Nihon Univ College of Bioresource Sciences, Fujisawa City, Kanagawa, Japan.

23. Global Rice Science Partnership (2013) Rice Almanac, 4th edn, International Rice Research Institute: Los Baños, Philippines.

24. Phattarakul N, Rerkasem B, Li L, Wu L, Zou C, Ram H, Sohu V, Kang B, Surek H, Kalayci M (2012) Biofortification of rice grain with zinc through zinc fertilization in different countries. Plant Soil 361, 131-41. 